\title{
PERFIL, MOTIVAÇÃO E SATISFAÇÃO DO CONSUMIDOR VEGANO/VEGETARIANO NO MUNICÍPIO DE INDAIATUBA/SP
}

\author{
MOTA, Isabel Carolina Carvalho ${ }^{1}$ \\ COSTA, Barbara Regina Lopes ${ }^{2}$ \\ ARAÚJO, Richard Medeiros de ${ }^{3}$
}

Recebido em: 2020.09.17 Aprovado em: 2021.04.27 ISSUE DOI: $10.3738 / 1982.2278 .3847$

\begin{abstract}
RESUMO: O objetivo deste estudo é analisar as variáveis que definem o perfil, motivação e satisfação do consumidor vegano referente à oferta de bares e restaurantes no município de Indaiatuba/SP. Embora o foco deste estudo seja o veganismo, a amostra contemplou os vegetarianos também, pois o segmento vegano é vegetariano por natureza e a transição do vegetarianismo para o veganismo é um comportamento ordinário. Este estudo aborda os principais conceitos sobre veganismo, segmentação de mercado e perfil do consumidor, assim como o breve resumo sobre o conceito e histórico do mercado vegano, o cenário atual brasileiro e o mercado vegano no município de Indaiatuba/SP. Metodologicamente foi um estudo com enfoque misto, sendo exploratória e descritiva, dada a contemporaneidade do tema e por expor características de determinada população. O questionário eletrônico continha 16 questões, a maioria de múltiplas escolhas, que geraram dados tratados por meio de estatística descritiva. Os resultados demonstram que, motivados pelos valores pessoais e a preocupação com o meio ambiente, os consumidores veganos estão insatisfeitos, sendo premente a necessidade de ampliar as opções existentes nos cardápios dos bares e restaurantes da cidade, bem como adaptações para atender o público vegano/vegetariano e entendimento sobre as limitações desses consumidores. Constatou-se também que ainda se trata de um perfil com características com baixa incidência ou um grupo social mais restrito, evidenciando um segmento com poucos adeptos (veganos), mas em expansão.
\end{abstract}

Palavras-chave: Alimento saudável.Mudança de hábito. Processo de Compra.

\section{PROFILE, MOTIVATION AND SATISFACTION OF THE VEGAN/VEGETARIAN CONSUMER IN THE CITY OF INDAIATUBA / SP}

\begin{abstract}
SUMMARY: The aim of this study is to analyze the variables that define the profile, motivation and satisfaction of the vegan consumer regarding the offer of bars and restaurants in the municipality of Indaiatuba/SP. Although the focus of this study is veganism, the sample included vegetarians as well, since the vegan segment is vegetarian by nature and the transition from vegetarianism to veganism is an ordinary behavior. This study addresses the main concepts on veganism, market segmentation and consumer profile, as well as the brief summary on the concept and history of the vegan market, the current Brazilian scenario and the vegan market in the municipality of Indaiatuba/SP. Methodologically it was a study with a mixed focus, being exploratory and descriptive, given the contemporaneity of the theme and for exposing characteristics of a certain population. The electronic questionnaire contained 16 questions, most of them with multiple choices, which generated data by means of descriptive statistics. The results demonstrate that, motivated by personal values and concern for the environment, vegan consumers are dissatisfied, and there is an urgent need to expand the options available in the menus of bars and restaurants in the city, as well as adaptations to serve the vegan public / vegetarian and understanding about the limitations of these consumers. It was also found that it is still a profile with low incidence characteristics or a more restricted social group, showing a segment with few followers (vegan) but expanding.
\end{abstract}

Keywords: Healthy food. Change of habit. Purchase process.

$1 \quad$ Graduada em Comércio Exterior (2016) e em Gestão Empresarial (2020)

2 Doutora em Administração - Universidad de la Empresa (UDE), mestrado em Administração pela Universidade Municipal de São Caetano do Sul (USCS), especialização em Marketing pelo Centro Universitário da FEI e em Comunicação Empresarial pela Faculdade Cásper Líbero, graduação em Comunicação Social / Publicidade e Propaganda e em Administração

${ }^{3}$ Doutor em Administração pelo PPGA/UFRN

Nucleus, v.18, n.1, abr. 2021 


\section{INTRODUÇÃO}

Embora a preocupação com o bem estar, integridade dos animais e dietas sem a ingestão de proteína animal tenham registros históricos seculares, é a partir do século XX que o não consumo de carnes, começou a ser associado a outros fatores, como a preservação ambiental e os direitos animais. No Brasil, 14\% da população já se declara vegetariana (PESQUISA..., 2018). Tais preocupações ajudaram a construção do veganismo, como estilo de vida e segmentação de mercado.

Conforme o Vegan Society (2020) - instituição pioneira que registrou a definição do veganismo - "o veganismo é um modo de vida que procura excluir, na medida do possível e praticável, todas as formas de exploração e crueldade com os animais para a alimentação, vestuário ou qualquer outro tipo de produto/consumo oriundo de animais". Não existe uma data para o início do veganismo (VEGAN SOCIETY, 2014), mas se sabe que essa opção de dieta vegana é antiga, presente em algumas sociedades, culturas e adotada por personalidades como o filósofo e matemático grego Pitágoras e por Buda (GALISA; ESPERANÇA; SÁ, 2007; CASTRO, 2018). Porém, o assusto começou a se tornar mais popular nos últimos anos (RADNITZ, BEEZHOLD, DIMATTEO, 2015), ganhando apoio de médicos e especialistas que passaram a se opor publicamente ao consumo de algumas proteínas animais (FERNANDES, 2019). Os dados do Google Trends (2018 apud SVB, 2020) mostram o crescimento no volume de buscas pelo tema 'vegano', que tem aumentado de duas a três vezes a cada ano, em relação ao ano anterior (crescimento anual nas buscas entre $150 \%$ e $250 \%$ ).

Segmento de mercado é a divisão de um mercado em grupos menores e específicos de consumidores, que agem e consumem de acordo com seus valores, interesses e hábitos. Assim a segmentação é considerada uma estratégia para alocar recursos de marketing, tendo a capacidade para o delineamento das oportunidades de negócio, com base nas diferenças entre os grupos de compradores, separando-os em estratos, de maneira que a empresa possa escolher e voltar seus esforços para aqueles nos quais sua produção receberá maior atenção, determinando consequentemente uma política competitiva (SIQUEIRA, 2005; COSTA, 2010).

Estudos sobre os consumidores devem ser feitos, pois qualquer que seja a oferta é destinada a um comprador que possui demandas funcionais e/ou emocionais que influem diretamente no processo de venda e compra. Além disso, compreender o consumidor do século 21, que munido “do poder da informação, já começa a impor uma série de necessidades e desejos, que vão além de produtos ou serviços de qualidade" se torna indispensável a inovação e sobrevivência empresarial (COSTA; PICCHI, 2017, p.22). Neste contexto, “o ativismo alimentar tem sido apontado como um dos movimentos contemporâneos mais dinâmicos e heterogêneos, que discute questões ambientais, sociais, morais, éticas, econômicas e culturais" (HÖLZER, 2018, p. 01). 
Diante do cenário exposto, busca-se conhecer um pouco mais do perfil do consumidor vegano e suas motivações. Considerando que o contexto social facilita e motiva o consumo vegano, uma vez que esse tem práticas de consumo particulares, identidades que moldam a maneira como consomem e fazem parte desse movimento cultural em ascensão (FULLER, 2016). Sendo assim, as empresas tendem a procurar formas de melhorar a oferta de seus produtos e serviços, buscando a satisfação dos segmentos. No Brasil, já é possível encontrar restaurantes vegetarianos e alguns poucos veganos, além de, estabelecimentos que trabalham com opções sem carne. $\mathrm{O}$ mercado de produtos veganos não atinge somente um público específico, mas também uma parcela da população que busca reduzir o consumo de carnes, leite/derivados e ovos, incluindo aqueles com algum grau de intolerância à lactose e/ou proteína animal.

Para maior explicitação, a abordagem deste estudo teve foco na oferta de bares e restaurantes voltados aos consumidores vegetarianos e veganos no município de Indaiatuba/SP, uma vez que o segmento vegano é vegetariano por natureza e a transição do vegetarianismo para o veganismo é um comportamento ordinário, assim o objetivo desta pesquisa é analisar as variáveis que definem o perfil, motivação e satisfação do consumidor vegano referente a oferta de bares e restaurantes no município de Indaiatuba/SP.

Indaiatuba é um município brasileiro no interior do estado de São Paulo, pertence à RMC - Região Metropolitana de Campinas e possui uma população estimada de 201.619 mil habitantes (IBGE, 2020a). No município ainda não existe um guia gastronômico que avalia e registra de forma completa os estabelecimentos da cidade que são veganos ou que oferecem opções para este público. Os três melhores estabelecimentos com opções vegetarianas em Indaiatuba/SP são: Casa da Esfiha, especializado em comida do oriente médio e mediterrânea, o restaurante Amadeu, onde é possível encontrar opções brasileira, sul-americana e contemporânea e o La Fee Cafeteria e Restô, com opções de cafés, comida nacional, para o almoço e jantar, e doces (ENCONTRE... 2019).

Ao proporcionar maior e melhor compreensão das demandas individuais e sociais dos consumidores veganos, além de consolidar estudos anteriores, esse paper fornece novas informações que contribuirá com futuros estudos e que também podem ampliar a visão mercadológica.

\section{REVISÃO DA LITERATURA}

\subsection{Segmentação de mercado}

Segmentar um mercado é o: 
Processo de agregação de consumidores com características homogêneas, diferenciadas de outros grupos, com o objetivo de planejar programas de marketing que se aproximem mais da satisfação de desejos e necessidades do grupo ou grupos escolhidos como mercado-alvo (LAS CASAS, 2009, p. 114).

Com base nesta abordagem o mercado é dividido e subdividido conforme a variedade de produto/serviço ofertada, bem como gostos, hábitos, valores e poder aquisitivo diferente dos grupos de consumidores.

Por isso, identificar o que cada cliente ou um grupo de clientes quer, suas exigências e desejos pessoais diminuem gastos com ofertas que não se adéquam ao mercado, podendo tornar o negócio especializado no atendimento das tais demandas e líder neste segmento. No entanto, toda estratégia mercadológica há desvantagens a serem consideras, como apostar em um único mercado, arriscando todos os esforços em um mesmo público e perde-lo com o aumento da concorrência, devido ao afunilamento do público escolhido e o mercado não ser suficientemente forte para ser dividido (COSTA, 2010).

Como as empresas não conseguem agradar todas as pessoas da mesma forma, é preciso identificar um ou mais grupos de pessoas com características que se coadunam com as possibilidades produtivas de oferta, sejam de natureza pessoal, como fisiológicas, demográficas, intelectuais, de personalidade e de hábitos, bem como de natureza ambiental, como geográficas, climáticas, culturais, de agrupamento social e de referência (LIMEIRA, 2017; SOLOMON, 2016; BLACKWELL; MINIARD; ENGEL, 2008).

O perfil do consumidor mudou e continua mudando, como saldo da exposição dos consumidores a contextos informativos, a disponibilidade de ampla variedade de bens e serviços, dentre outras transformações sociais, culturais, políticas e tecnológica (COSTA, PICCHI, 2017) e o veganismo passou a ser bem mais do que apenas um estilo de vida, gradualmente se transformou em novo modelo de negócios em todo o mundo. Pessoas vêm ficando mais conscientes e interessadas em reduzir o consumo de carne, e já começam a buscar alternativas no mercado que estejam mais alinhadas com o que elas acreditam ser eticamente corretas. É possível afirmar que algumas empresas devem se adaptar para atender esse público, vegano, ou poderão ficar para aquém na competição com outras marcas que tiverem uma preocupação sustentável e inclusiva.

\subsection{Veganismo}

Como prática, principalmente alimentar, tem registros históricos do veganismo desde civilizações antigas. Por influência do budísmo e do hinduísmo, foram adotadas na Índia as primeiras leis de proteção animal, no século II a.C. (BASTOS, 2016; CASTRO, 2018). Porfírio, 
Plutarco, Platão e Sêneca também defendiam o vegetarianismo filosófico (CASTRO, 2018). No Renascimento, Leonardo da Vinci e outros pensadores e artistas do século XV fizeram reacender o vegetarianismo e outras práticas contra os mals tratos a animais (SARAIVA, 2014). Muitos outros foram os pensadores que trataram "a questão dos animais criticamente - ainda que de maneira não sistemática -, reivindicando para eles um lugar além de meros objetos”, dentre eles: William Shakespeare, Michel de Montaigne, Isaac Newton, Rousseau, Voltaire, Arthur Schopenhauer, John Stuart Mill, Charles Darwin, Albert Einstein e Mahatma Gandhi (SARAIVA, 2014, p. 11).

O veganismo é um movimento social a respeito dos direitos animais, que pratica o fim do uso de animais para alimentação, apropriação, trabalho, caça, confinamento e todos os outros usos que envolvam exploração da vida animal. Os veganos atuam pela abolição de qualquer prática que explore animais, zelando pela preservação da liberdade e integridade animal, assim boicotam qualquer produto de origem animal (seja alimentos ou não), além de serviços e produtos que tenham sido testados em animais ou que incluam qualquer forma possível de exploração animal nos seus ingredientes e/ou processos (VEGAN SOCIETY, 2014; ABV, 2020).

Imbuído desta causa, esse modo de vida, dispensa todos os produtos derivados de animais e serviços correlatos, como destaca a Associação Brasileira de Veganismo (ABV, 2020):

- Carnes de todas as cores e tipos;

- Alimentos de origem animal ou que contenham qualquer resíduo, como leites, queijos, manteiga, salsichas, ovos, albumina, mel, banha, corante cochonilha, gelatina, etc.

- Roupas, sapatos e acessórios feitos de partes dos corpos de animais, como couro, seda e lã;

- Cosméticos e medicamentos testados em animais ou que contenham componentes animais na formulação, como sabonetes feitos de glicerina animal, maquiagem contendo cera de abelha, xampu com tutano de boi, etc;

- Não apoiar diversões contendo exploração animal, como pesca, caça, circos com confinamento de animais, zoológicos, rodeios, rinhas, etc;

-Evitar trabalhar profissionalmente, com exploração animal (vivo ou morto), como em pet shop e demais lojas que tenha venda de animais ou gaiolas para passarinhos, aquários ou equipamentos para pesca ou caça. Bem como em lojas que venda qualquer produto que contenha derivado animal, como bolsas e cintos de couro legítimo ou em restaurante que utilize animais ou seus resíduos corporais como comida, dentre outras atividades.

Embora para muitos haja consenso que o "veganismo é uma forma extrema de vegetarianismo" (SUDDATH, 2008) e seja inegável que o veganismo tenha forte relação com o vegetarianismo, é preciso diferenciar tais práticas e movimentos sociais, enquanto o primeiro foca sua atenção em atitudes, direitos e consumo, buscando uma vida humana em harmonia com a 
vida dos animais, sem a necessidade de subjugação ou consumo de animais ou derivados, o segundo está diretamente ligada a dieta que exclui todos os tipos de carne, peixe, leite e ovos. Desta forma, é correto afirmar que a sociedade vegana é vegetariana, mas não o contrário.

$\mathrm{O}$ vegetarianismo iniciou com o argumento antropocêntrico de que matar animais para consumo humano promove o desenvolvimento de hábitos indesejáveis em humanos (STEFAN et $a l, 2018$ ), modificando-se ao longo do tempo, passando pela preocupação com o sofrimento que os animais vivenciam no abate e mais recentemente inclui a conscientização referente ao impacto que o consumo maciço de carne tem no meio ambiente, desde o desmatamento para a criação de animais e a emissão de poluentes resultantes do processamento e do consumo da carne (SILVA, 2019). Como organização civil, o vegetarianismo começou a consolidar-se com fundações de sociedades vegetarianas em diversos países, no século XIX.

Um século depois, com base em ações e propostas das sociedades vegetarianas tem-se a construção do conceito vegan ou veganismo, além da fundação da Vegan Society, em Londres, no ano de 1944. De acordo com o Suddath (2008) e Vegan Society (2014), Donald Watson foi responsável pelo novo termo - vegan (vegano), referindo-se às pessoas que além de não consumirem alimentos de origem animal tem como princípio a emancipação da exploração dos animais pelo homem. Em 1979, a Sociedade Vegana informou que, além da exclusão de todas as formas de exploração e crueldade, eles se dedicariam a promover o desenvolvimento e criação de alternativas sem uso de animais, beneficiando também o meio ambiente (VEGAN SOCIETY, 2014).

Com o crescimento do veganismo no mundo, a Vegan Society instituiu, em $1^{\circ}$ de novembro de 1994, o Dia Mundial Vegano, em comemoração aos 50 anos de fundação da entidade (SUDDATH, 2008; VEGAN SOCIETY, 2014).

\subsubsection{Mercado Vegano Brasileiro}

No Brasil, ainda não há dados específicos, nem mesmo a quantificação dos veganos, mas, uma estimativa da Sociedade Vegetariana Brasileira (SVB, 2020) considera de forma conservadora que $33 \%$ dos vegetarianos brasileiros sejam veganos, resultando em aproximadamente 7 (sete) milhões de brasileiros (IBGE, 2020b).

Cortiñas Lopez e Gama (2010, p. 68) explicam que o mercado é “o conjunto de características e tendências ditadas pelos consumidores que o compõem”. Dessa forma, quando pessoas imbuídas da causa e, assim, adeptas ao modo de vida vegana passam a requerer novos alimentos, produtos e serviços específicos, o veganismo se torna um segmento de mercado, que vai além do tradicional universo vegetariano. Observando o mercado, indústrias alimentícias 
buscam soluções como o desenvolvimento de alimentos e bebidas em laboratório. A Tyson Foods, uma das maiores processadoras de carnes de animais do mundo, está investindo na carne de laboratório Beyond Meat, carne de origem vegetal (MINTEL, 2018).

A Sociedade Vegetariana Brasileira é entidade responsável pela certificação de produtos veganos no Brasil, selo entregue mediante uma análise rigorosa da cadeia produtiva, com taxas que variam de $\mathrm{R} \$ 300$ a $\mathrm{R} \$ 1$ mil, dependendo do tamanho da empresa. O mercado voltado para o público vegano vem ganhando espaço e já há algumas marcas nacionais 100\% veganas de alimentos, roupas, sapatos, produtos de higiene e limpeza e diversos outros produtos (MINTEL, 2017).

De acordo com Picciarelli (2019) os dados reforçam que 47\% dos brasileiros têm procurado substituir carne por alimentos vegetais e $22 \%$ preferem não comer carne, frango ou peixe e a pesquisa Global Food and Drink Trends (MINTEL, 2017) aponta a preferência por dietas naturais, simples e flexíveis, impulsionando a expansão do mercado de produtos de origem vegetal. Assim as empresas visionárias não se limitam ao leite vegetal e estão disponibilizando ao mercado diversas opções de pratos sem componentes de origem animal.

Uma das maiores marcas de alimentos vegetarianos e veganos brasileira é a Superbom, que conta com 95 produtos em mais de 25 mil pontos de venda (PRADO, 2016). A Mr. Veggy que possui como valores, o amor aos animais, equilíbrio, qualidade e tolerância, é outra empresa que cresce a cada ano. Nos seus cinco primeiros anos, cresceram cerca de $40 \%$ e atualmente faturam em torno de $\mathrm{R} \$ 200$ mil por mês, oferecendo dezenas de pratos congelados e adaptados, com certificação de soja não transgênica e demais ingredientes in natura. Interessante destacar, que a Mr. Veggy, não atua somente no varejo e parte do seu faturamento vem do atendimento a mais de 600 empresas, como Google, Mercedes Benz e hospitais (SOBRE... 2020; EMPRESAS... 2016).

Mas, não é apenas o setor alimentício que está em voga neste novo mercado, a Surya Brasil é pioneira no ramo de cosméticos veganos, utilizando insumos de agricultura orgânica. Com o aumento de feiras e eventos específicos ao segmento, esse mercado passou a ser mais expressivo e atualmente a Surya Brasil exporta para 40 países (PRADO, 2016).

Vale considerar que o mercado vegano também atende consumidores não veganos, que estão preocupado em consumir produtos socioambientais sustentáveis, indo além de saciar as necessidades primárias de subsistência. Schinaider (2018, p. 59) ratificou em seu estudo que a preocupação com o meio ambiente é uma das principais motivações dos consumidores veganos do Brasil, "os consumidores veganos associam os produtos veganos como alimentos eco inovadores, considerados éticos, saudáveis e sustentáveis", e com esse apelo agregam demais consumidores envolvidos com a causa ambiental.

O interesse e consumo destes produtos não é exclusividade dos veganos, pessoas com doenças relacionadas à alimentação como intolerância à lactose ou alergias a qualquer outro 
ingrediente de origem animal, e pessoas a procura de alimentos saudáveis, buscam produtos alternativos contribuindo com promissoras oportunidades de negócio nesta área.

Um estudo realizado pelo IBOPE (PESQUISA... 2018) levantou que 55\% dos entrevistados consumiriam mais produtos veganos (sem nada de origem animal) se houvesse uma melhor sinalização nas embalagens e 60\% daria preferência a eles, na hora da decisão de compra, se os produtos veganos tivessem o mesmo preço dos produtos de origem animal que eles estão acostumados a consumir. Nas capitais, o percentual de entrevistados que daria preferência aos produtos veganos se eles tivessem o mesmo preço dos não veganos chegou a $65 \%$.

A ABIHPEC e SEBRAE (2020) confirmam como tendência as exigências crescentes dos consumidores por matérias-primas de origem natural, vegetal e orgânica. Assim, a demanda por estes produtos é maior que a oferta no país, conforme a Associação Brasileira de Supermercados (ABRAS, 2017), corroborando com a necessidade de estudos que versem sobre o consumidor neste segmento de mercado.

\section{MÉTODO DA PESQUISA}

Conforme temática e o objetivo do estudo, a caracterização da pesquisa possui enfoque misto, sendo exploratória, dada a sua contemporaneidade e descritiva.

Fez-se uma revisão na literatura relacionada à economia e segmentação de mercado, perfil do consumidor, estratégia empresarial, empresas e associações que estudam o consumidor vegano.

Embora o foco deste estudo seja o veganismo, foram definidos como sujeitos da amostra os vegetarianos e veganos que frequentam bares ou restaurantes em Indaiatuba/SP, escolhidos pelo critério da participação voluntária, sem qualquer distinção, caracterizando uma amostragem não probabilística. A ampliação da amostra ocorreu uma vez que como subscrito no referencial teórico o segmento vegano é vegetariano por natureza.

$\mathrm{Na}$ terceira etapa foi elaborado um questionário como instrumento de coleta de dados, com intuito de analisar as variáveis que definem o perfil, motivação e satisfação do consumidor vegano no município de Indaiatuba/SP. O questionário foi configurado por meio da ferramenta Google Docs e a escolha se deu por possibilitar a formatação, coleta rápida de dados e visualização, sendo gratuita.

O questionário é formado por 16 questões, a maioria de múltipla escolha, 08 visavam definir características demográficas, sendo utilizado também os critérios de classificação econômica estabelecidos pela Associação Brasileira de Empresas de Pesquisa (ABEP), e 8 questões foram direcionadas a responder as variáveis que afetam o consumo (motivação e 
satisfação) do segmento vegano/vegetariano referente a oferta de bares e restaurantes no município de Indaiatuba/SP. Visando que os participantes se sentissem mais confiantes em fornecer informações, o questionário garantiu o anonimato. A aplicação deu-se no mês de outubro de 2019, durante 15 dias.

Na sequência foi decidido os campos de divulgação do link do instrumento de coleta de dados: As redes sociais virtuais e através de cartazes com QR CODES (Quick Response Codes ou Códigos de Resposta Rápida) afixados em alguns pontos da cidade, bem como nos murais da Faculdade de Tecnologia de Indaiatuba, de uma escola de ensino infantil, de uma escola de idiomas e em duas lanchonetes, visando atingir o maior número de vegetarianos/veganos.

As redes sociais virtuais é uma forma de acesso ao público e de visualização rápida do instrumento, pois como pontua Costa (2018), as redes sociais virtuais passaram a fazer parte do cotidiano das pessoas. O levantamento de dados por meio das redes sociais virtuais é conhecido como método Bola de Neve Virtual. Segundo Costa (2018, p. 19) "o que diferencia o método Bola de Neve dos demais métodos de coleta de dados, é a formação da amostra, a qual se dá ao longo do processo e não é determinada previamente". O método de levantamento de dados Bola de Neve Virtual inicia-se pela apresentação do link de acesso ao questionário eletrônico, com uma breve explicação do estudo e o convite à participação, e finaliza como o pedido para que as pessoas compartilhem o post ou o link da pesquisa, criando um processo pelo qual pessoas interessadas envolvam outras de forma viral.

O texto de apresentação do link e do QRCode, foi elaborado para evidenciar o público alvo, tendo o título escrito em caixa alta "VOCÊ É VEGETARIANO OU VEGANO?", na sequência, foi apresentado o estudo, que novamente esclarecia que o objetivo era definir o perfil dos veganos/vegetarianos que frequentavam bares e restaurantes em Indaiatuba.

Por fim, os dados foram tratos por meio de estatística descritiva, que objetiva sintetizar os dados e possibilitar interpretação, por meio da quantificação do objeto.

\section{ANÁLISE E DISCUSSÃO DOS DADOS}

Respondido por 120 consumidores que se consideram veganos ou vegetarianos, o questionário estava dividido em duas partes. A primeira para identificar o perfil das pessoas veganas e vegetarianas que responderam o instrumento, apresentando dados sobre idade, identidade de gênero, cidade onde mora e classificação social. A segunda parte do questionário, está relacionada com a motivação e satisfação do público vegetariano e vegano em relação às ofertas de bares e restaurantes no município de Indaiatuba/SP. 
A maioria do público, vegano e vegetariano, que participou do estudo, estão entre 21 a 27 anos de idade, correspondendo a 35\% da pesquisa. Logo após, a segunda faixa etária com mais respondentes $(23,5 \%)$ está com idade entre 15 a 20 anos.

De acordo com Vegavida.com (2018), uma pesquisa feita com cerca de 1800 famílias, descobriu que mais da metade dos pais que compram alimentos orgânicos e sem produtos de origem animal fazem parte da chamada Geração do Milênio, nascidos a partir de 1980 (OLIVEIRA, 2010). A pesquisa também afirma que essa geração pesquisa mais do que qualquer outra geração, antes de decidir qual produto ou alimento comprar. Assim, a tendência é de que nos próximos dez anos, até $50 \%$ da produção varejista se concentrará em produtos frescos, locais, orgânicos, naturais ou saudáveis. Ainda de acordo com essa mesma pesquisa, 77\% dos questionados afirmaram saber o suficiente sobre alimentação orgânica e sem origem animal.

A identidade de gênero dos participantes da pesquisa, contou com 76,3\% de respondentes do sexo feminino, $21,3 \%$ do sexo masculino e uma menor porcentagem $(2,4 \%)$ marcou outras identidades de gênero.

Dois estudos feitos na região metropolitana de São Paulo identificaram o perfil de vegetarianos e veganos, tendo predominância de jovens (idade média de 29 anos; 53\% têm de 18 a 25 anos e 30\% entre 26 e 35 anos) e do gênero feminino (70\% e 87\%) (NUNES, 2010; QUEIROZ; SOLIGUETTI; MORETTI, 2018), ratificando os dados apurados por esse estudo. Bandeira (2019) argumentou que um dos motivos do maior engajamento feminino na causa vegana é a associação da carne com a masculinidade, o "homem caçador", com a imagem do homem forte com o consumo de proteína animal. Outro motivo seria que as mulheres costumam ter maiores cuidados com a saúde do que os homens, vivenciaram a pressão pela magreza, para se adequar aos padrões de beleza, e assim enxergam no veganismo uma oportunidade para emagrecer mais rápido (BANDEIRA, 2019).

Com relação a cidade de residência dos respondentes, a maioria mora em Indaituba/SP e $15 \%$ dos respondentes moram em outras cidades, mas são frequentadores de bares e/ou restaurantes de Indaiatuba.

Para identificar a classificação econômica dos respondentes, foi utilizado o Critério de Classificação Econômica Brasil (CCEB), da ABEP, que estima o poder de compra das pessoas e famílias urbanas, sem a pretensão de classificar a população em termos de "classes sociais". Segundo a ABEP (2019), o CCEB é um instrumento de segmentação econômica que utiliza o levantamento de características domiciliares (presença e quantidade de alguns itens domiciliares de conforto e grau escolaridade do chefe de família) para diferenciar a população. O critério atribui pontos em função de cada característica domiciliar e realiza a soma destes pontos. É feita 
então uma correspondência entre faixas de pontuação do critério e estratos de classificação econômica definidas por A, B1, B2, C1, C2 e DE.

A classe econômica da maioria dos participantes da pesquisa é a B1 (58\% dos respondentes), correspondente a apenas $5,6 \%$ da população do sudeste brasileiro ou 7,4\% da população da região metropolitana de São Paulo (ABEP, 2019).

Apesar de terem semelhanças, os grupos alimentares que não consome proteína animal, divergem em alguns pontos, formando identidades completamente diferentes para os indivíduos que fazem parte destes grupos. O grau de restrição a produtos de origem animal é o que determina o tipo de vegetarianismo, que pode variar desde os ovolactovegetarianos, que consomem os produtos derivados de animais, até os veganos que não consomem nenhum produto de origem animal (NASCIMENTO, 2007).

Esse estudo contou com apenas $10 \%$ dos respondentes que seguem o estilo de vida vegano, que procuram "excluir, na medida do possível e praticável, todas as formas de exploração e crueldade com os animais" (VEGAN SOCIETY, 2020), 14\% são vegetarianos, indivíduos que não ingere nenhum tipo de carne (boi, suínos, aves, peixes, frutos do mar, etc) e também não consome os derivados, como ovo e leite (UVI, 2017). A maior parte dos participantes (39\%) são ovolactovegetarianos, que excluem a carne, inclusive os frutos do mar, mas não exclui leite e ovos; $37 \%$ ainda estão no processo de transição, isso significa que estão cortando a ingestão de proteína animal, mas ainda comem em alguns casos ou aqueles que não comem outros tipos de carne, porém consomem peixe.

Vale observar que na metodologia, previamente definida para esse estudo, fica esclarecido que na mensagem convite para responder ao questionário foi evidenciado a participação exclusiva de vegetarianos e veganos, assim os consumidores em transição não foram descartados do grupo amostral, uma vez que eles já se consideram e se posicionam como vegetarianos e também ponderando o viés do estudo no contexto empresarial, pela perspectiva mercadológica, tais consumidores já são pertencentes ao segmento vegetariano.

Uma pergunta de múltipla escolha verificou que existem algumas razões para deixar de consumir produtos animais e derivados, sendo as principais:

- Ética: A maioria dos participantes da pesquisa (85\%) valoriza o bem-estar animal, com um posicionamento contrário a qualquer tipo de crueldade contra os seres vivos, tanto em relação ao abate quanto à exploração de animais, corroborando com o posicionamento dos membros do segmento vegano.

- Meio Ambiente: a segunda opção mais apontada (62\%) entre os respondentes. A Sociedade Vegan (2017), alerta que $70 \%$ dos cereais plantados são usados para alimentar os animais de criação intensiva, o que poderia ajudar a alimentar grande parte das populações que 
morrem de fome. Na pecuária industrial, para produzir 1 quilo de carne são necessários 15 mil litros de água, enquanto que para produzir 1 quilo de cereais, precisa de 1,3 mil litros de água, outra comparação é que em um hectare de terra podem ser plantados 22,500 quilos de batata, enquanto que na mesma área apenas se produz 185 quilos de carne bovina (FAO, 2019).

- Saúde: razão escolhida por 54\% dos participantes deste estudo. De acordo com a Sociedade Vegan (2017), a dieta vegetariana é muito mais saudável, cortar o consumo de animais reduz o risco de ter colesterol alto, previne vários cancros, aumenta a energia e ajuda a controlar o peso. O consumo de mais alimentos naturais, ricos em fibras, nutrientes e sem processamento, regula o funcionamento do organismo, reduz as taxas de açúcar no sangue e promove maior saciedade.

A maioria dos respondentes, representando $88 \%$ dos participantes, frequentam bares ou restaurantes em Indaiatuba/SP. Novamente é preciso resgatar a metodologia definida, bem como a mensagem convite aos voluntários para participar desse estudo, 'vegetarianos e veganos que frequentassem bares e restaurantes no município de Indaiatuba/SP'. Outros estudos que também utilizaram as redes sociais virtuais como campo para coleta de dados também tiveram a participação voluntária de pessoas que não se enquadram no perfil especificado no convite a participação, como verificou Costa (2018). Prevendo essa possibilidade, o questionário era encerrado automaticamente para quem respondesse que "não" frequenta bares ou restaurantes em Indaiatuba/SP.

Desta forma a amostra, não probabilística, que contribui na análise da oferta de bares e restaurantes que são frequentados por consumidor vegano e vegetariano no município de Indaiatuba/SP, conta com 96 participantes voluntários.

Visando identificar a frequência que os vegetarianos e veganos vão a bares ou restaurantes em Indaiatuba/SP, apurou-se: que a maioria (32\%) frequenta uma ou duas vezes por mês, $26 \%$ vão aos estabelecimentos todos os finais de semana, $16 \%$ uma ou duas vezes por semana e $24 \%$ raramente. Se alimentar em restaurantes, lanchonetes e demais estabelecimentos que oferecem o serviço fora do lar, exige algumas habilidades dos vegetarianos e veganos, já que o controle no preparo das refeições está nas mãos de outra pessoa. Porém, seja por prazer ou necessidade do dia a dia, almoçar em restaurantes onívoros pode ser uma prática rotineira.

Uma questão perguntava se eles encontravam opções vegetarianas e veganas nos bares e restaurantes frequentados em Indaiatuba/SP, apurou que maioria $(76 \%)$ encontram as opções específicas. No entanto, embora haja alternativas, $81 \%$ dos participantes deste estudo afirmaram que não estão satisfeitos com as opções disponíveis nos estabelecimentos da cidade. Evidenciando que bares e restaurantes de Indaiatuba/SP precisam se adaptar ao perfil dos 
consumidores veganos e vegetarianos, buscando compreender o seu processo de compra, necessidades e valores.

Para entender os motivos da insatisfação diante das ofertas de bares e restaurantes voltados ao consumidor vegano e vegetariano no município de Indaiatuba/SP, a questão de múltipla escolha registrou que 81,2\% dos participantes aspiram pela ampliação das opções no cardápio, 70,5\% apontam a necessidade de maior adaptação para atender ao público vegetariano e vegano e 56,2\% escolheram a opção "Buscar entender as limitações do público vegetariano/vegano".

Para finalizar, a última pergunta do questionário eletrônico, uma questão aberta que buscava identificar possíveis sugestões de melhorias advindas dos consumidores veganos e vegetarianos, para os bares e restaurantes na cidade de Indaiatuba/SP. Essa questão ratifica os motivos de insatisfação verificada anteriormente, uma vez que as respostas embora apresentem redações diferentes fazem dois apelos 'incluir mais diversidade e sabor nas opções veganas e vegetarianas' e 'aumentar o interesse por esse segmento de mercado'. As respostas dos participantes focaram além do aumento de variedades, melhores preços e a necessidade de mais empreendedores na área.

\subsection{Compilação dos dados apenas dos veganos}

Embora a participação dos veganos tenha sido de 12 veganos no universo de 120 pesquisados, para atender ao objetivo do estudo se faz necessário a compilação dos dados destes 12 veganos que participaram voluntariamente da amostra. Vale ressaltar que, em conformidade com a metodologia, se trata de uma amostra não probabilística, o que inviabiliza a generalização dos resultados para descrever, em sua totalidade, o perfil dos veganos que frequentam bares e restaurantes de Indaiatuba/SP, no entanto, outros estudos foram apresentados preliminarmente ampliando a discussão.

A maioria é mulher (83\%), variando entre idades de 21 a 27 anos (42\%) e 35 a 42 anos $(33 \%)$, moradoras da cidade alvo do estudo (83\%) e pertencentes a classificação econômica B1 (83\%) da ABEP.

O grupo vegano apresenta como motivações para deixar de consumir produtos de origem animal e/ou derivados a Ética (100\%), o Meio Ambiente (66\%), o desejo de Espalhar Compaixão $(58 \%)$ e, ratificando as motivações de combater a mudança climática, a Economia de Água (33\%). A preocupação com a Saúde $(16,5 \%)$ foi citado por 2 pessoas, mas sem o objetivo da Perda de Peso, pois ninguém assinalou essa opção.

Todos são frequentadores de bares e/ou restaurantes na cidade de Indaiatuba, sendo que $50 \%$ frequentam raramente, encontra partida, 33,5\% frequentam todos os finais de semana e 
16,5\% vão aos estabelecimentos 1 ou 2 vezes por semana. Da mesma forma, a pergunta "Existem opções vegetarianas/veganas nos bares e restaurantes frequentados em Indaiatuba/SP?” dividiu exatamente as opiniões. Talvez porque a pergunta inclui os vegetarianos, pois na pergunta seguinte todos os veganos (100\%) afirmam não estar satisfeito(a) com as opções vegetarianas/veganas nos bares e restaurantes frequentados em Indaiatuba/SP.

Eles consideram que os bares e restaurantes de Indaiatuba poderiam melhorar se adaptando para atender o público vegetariano/vegano (91,5\%), ampliando as opções no cardápio (75\%) e buscando entender as limitações do público vegetariano/vegano $(41,5 \%)$.

\section{CONSIDERAÇÕES FINAIS}

Esse trabalho objetivou analisar as variáveis que afetam a satisfação do consumidor vegano, buscando identificar o perfil do segmento vegano/ vegetariano, apontar os principais motivos que influenciam na mudança de hábitos e adesão ao veganismo, realizar um levantamento dos níveis de satisfação de tais consumidores quanto aos serviços de oferta de alimentação pronta (bares e restaurantes) existentes em Indaiatuba/SP e propor melhorias para esse segmento de mercado na cidade.

A satisfação do consumidor se dá quando há equivalência da experiência vivida com a oferta com a expectativa que se tinha. Constata-se que, a satisfação dos veganos e vegetarianos em Indaiatuba/SP está aquém do esperado. Fato importante a ser observado é que as variáveis que afetam esse nível de satisfação estão relacionadas com as opções existentes nos cardápios dos bares e restaurantes da cidade, faltando adaptações para atender o público vegano/vegetariano e entendimento sobre as limitações desses consumidores. Todos os veganos se declaram insatisfeitos com as ofertas.

Sendo assim, é possível afirmar que os bares e restaurantes de Indaiatuba precisam se adaptar ao perfil dos consumidores veganos e incentivá-los a frequentar mais os estabelecimentos, por meio da compreensão do seu processo de compra, necessidades e valores.

Em relação ao perfil, os consumidores veganos em Indaiatuba são jovens, a maior parte do sexo feminino e possuem poder aquisitivo muito superior a média da sociedade. Tais características também descrevem os consumidores vegetarianos.

As principais motivações que orientam e influenciam os consumidores veganos estão relacionadas aos valores pessoais (ética e compaixão) e a preocupação com o meio ambiente. A motivação "saúde", também declarada, está associada aos "alimentos ecoinovadores", uma vez 
que esses são considerados éticos, saudáveis e sustentáveis, possibilitando uma dieta sustentável, sob os aspectos sociais, econômicos e ambientais.

Para concluir a análise mercadológica, é possível afirmar que, as empresas devem se adaptar para atender esse segmento de mercado, buscando entender os fatores pessoais, socioculturais e psicológicos desse público ou poderão ficar para trás na competição com outras marcas que tiverem uma preocupação sustentável maior.

Dentre as limitações deste estudo está a pouca participação dos veganos, uma vez que ainda se trata de um perfil com características com baixa incidência ou um grupo social mais restrito, evidenciando um segmento com poucos adeptos (veganos) mas em franca expansão. Como forma de contribuir para futuros estudos sugere-se maior tempo de coleta de dados ou identificação de locais de encontro deste grupo social, como restaurantes ou lojas que atendem especificamente os veganos, para ser o campo de coleta de dados.

\section{REFERÊNCIAS}

ASSOCIAÇÃO BRASILEIRA DA INDÚSTRIA DE HIGIENE PESSOAL, PERFUMARIA E COSMÉTICOS - ABIHPEC; SERVIÇO BRASILEIRO DE APOIO ÀS MICRO E PEQUENAS EMPRESAS - SEBRAE. Caderno de Tendências 2019-2020. Disponivel em: < https://m.sebrae.com.br/Sebrae/Portal\%20Sebrae/Anexos/CADERNO\%20DE\%20TENDENCIA S\%202019-2020\%20Sebrae\%20Abihpec\%20vs\%20final.pdf>. Acesso em: 9 nov. 2019.

ASSOCIAÇÃO BRASILEIRA DE EMPRESAS DE PESQUISA - ABEP. Critério Brasil 2019. Disponível em: <http://www.abep.org/>Acesso em: 09 nov. 2019.

ASSOCIAÇÃO BRASILEIRA DE SUPERMERCADOS - ABRAS. Índice Nacional de Vendas 2017. Disponível em: 〈http://www.abras.com.br/economia-e-pesquisa/indice-de-vendas/>. Acesso em 02 nov. 2019.

ASSOCIAÇÃO BRASILEIRA DE VEGANISMO - ABV. O que é Veganismo. 2020 ?. Disponível em: <http://veganismo.aplace.com.br/veganismo/.> Acesso em: 15 abr. 2020.

BANDEIRA, Natasha. Especial dias das mulheres: por que as mulheres são a maioria no veganismo. 2019. Disponível em: <https://www.infoveggie.com/por-que-as-mulheres-saomaioria-no-veganismo>. Acesso em: 22 abr. 2020.

BASTOS, Elton. Como comer comida vegana em qualquer restaurante e ir além do alface. In: Veg News. Disponível em: <https://www.spveg.com/blog/va-alem-do-alface/>. Acesso em 24 abr. 2020.

BASTOS, Luiz Roclayton. Os animais não humanos como titulares de direitos no ordenamento jurídico brasileiro:. base histórico-filosófica e o acesso ao judiciário. Publicado em 08/2016. Disponível em: <https://jus.com.br/artigos/51511/os-animais-nao-humanos-como-

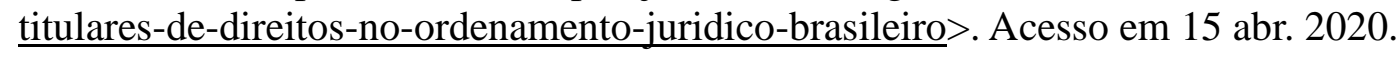


BLACKWELL, R. D.; MINIARD, P. W.; ENGEL, J. F. Comportamento do consumidor. 9. ed. São Paulo: Cengage Learning, 2008.

CASTRO, Márcia Marques Marinho et al. Com o coração na boca: pitagorismo, vegetarianismo e interfaces com a ética animal. 2018. Dissertação (Mestrado em Bioética, Ética Aplicda e Saúde Coletiva) - Universidade Federal Fluminense, UFF PPGBIOS, Niteroi, 2018.

CORTIÑAS LOPEZ, J. M; GAMA, M. Comércio exterior competitivo. São Paulo: Aduaneiras, 2010.

COSTA, Barbara Regina Lopes. Bola de Neve virtual: o uso das redes sociais virtuais no processo de coleta de dados de uma pesquisa científica. RIGS Revista Interdisciplinar de Gestão Social, São Paulo, v.7 n.1, jan./ abr. 2018.

COSTA, Barbara Regina Lopes. Fundamentos de marketing. 2.ed. Curitiba: Aymará, 2010.

COSTA, Barbara Regina Lopes; PICCHI, Danilo. As relações entre os consumidores do século 21 e as empresas, no âmbito da internet, pelas redes sociais virtuais. Revista da FAE, v. 20, n. 1, p. 7-26, 2017.

DIA munial do vegetariano: $8 \%$ da população brasileira afirma ser adepta do estilo. 2012. Ibope Inteligencia. Disponível em: <http://www.ibopeinteligencia.com/noticias-e-pesquisas/diamundial-do-vegetarianismo-8-da- populacao-brasileira-afirma-ser-adepta-do-estilo/>. Acesso em: 13 abr. 2019.

EMPRESAS focam no crescente mercado vegano. Globo News. Mundo S/A. 05/12/2016. Disponível em: <http://g1.globo.com/globo-news/mundo-sa/videos/t/mundo-sa/v/mundo-sa-empresasfocam-no-crescente-mercado-vegano/5494697/>. Acesso em: 21 abr. 2020. 1 video

ENCONTRE o restaurante perfeito. 2019. Tripadvisor. Disponível em: <https://www.tripadvisor.com.br/Restaurants- $\quad$ g303613-zfz10665Indaiatuba_State_of_Sao_Paulo.html>.Acesso em: 04 abr. 2019.

FERNANDES, Raphael. Universidades cariocas adaptam cardápios sem carne com crescimento de vegetarianos. Publicado em: 16/12/19. Disponível em:

$<$ https://querobolsa.com.br/revista/universidades-cariocas-adaptam-cardapios-sem-carne-comcrescimento-de-vegetarianos >. Acesso em: 11 abr. 2020.

FOOD AND AGRICULTURE ORGANIZARION OF THE UNITED NOTIONS - FAO.

Sustainable Food and Agriculture. 2019. Disponível em:< http://www.fao.org/sustainability/en $>$. Acesso em: 02 nov. 2019.

FULLER, J. The cultural creation of affect amongst vegan consumers: An ethnographic analysis of online consumption communities. Department of Service Management and Service Studies, Lund University, 2016.

GALISA, Mônica Santiago; ESPERANÇA, Leila Maria Biscólla; SÁ, Neide Gaudenci de. Nutrição: conceitos e aplicações. São Paulo: M.Books do Brasil, 2007. 
GERAÇÃO e o consumo consciente. Vegavida.com. Disponível em:

<https://www.vegavida.com.br/ageracao-y-e-o-consumo-consciente>. Acesso em: 05 nov. 2019.

HÖLZER, Maria Benedita de Lemos Magalhães Calem. Impacto do marketing e das marcas no processo de decisão de compra de alimentos para uma dieta de base vegetal. 2018. Dissertação (Mestrado). Instituto Superior de Contabilidade e Administração do Porto - Instituto Politécnico do Porto. Porto, 2018.

INSTITUTO BRASILEIRO DE GEOGRAFIA E ESTATISTICA - IBGE. IBGE Cidades Indaiatuba. 2020a. Disponível em: 〈https://cidades.ibge.gov.br/brasil/sp/indaiatuba/panorama〉 . Acesso em: 21 abr. 2020.

INSTITUTO BRASILEIRO DE GEOGRAFIA E ESTATISTICA - IBGE Projeção da população do Brasil e das Unidades da Federação. 2020b. Disponível em: <https://www.ibge.gov.br/apps/populacao/projecao/>. Acesso em: 21 abr. 2020.

LAS CASAS, Alexandre L. Marketing: conceitos, exercícios, casos. 8. ed. São Paulo: Atlas, 2009.

LIMEIRA, Tania Maria Vidigal. Comportamento do consumidor brasileiro. São Paulo: Saraiva Uni, 2017.

MARCONI, Marina de Andrade; LAKATOS, Eva. Maria. Fundamentos de metodologia científica. 5. ed. São Paulo: Atlas, 2003.

MINTEL. Brasil Tendências de Consumo. 2017. Disponível em:

<https://brasil.mintel.com/tendencias-de-consumo-2017>. Acesso em: 31 mar. 2020.

MINTEL.. Global Food \& Drink Trends. 2018. Disponível em:

$<$ https://gastronomiaycia.republica.com/wp-

content/uploads/2017/10/informe_mintel_tendencias_2018.pdf>. Acesso em: 24 mar. 2020.

NASCIMENTO, Ione Santos. Vegetarianos do Brasil consumo x produção de carne. Brasília: UNB/Centro de Desenvolvimento Sustentável, 2007.

NUNES E. L. M. Vegetarianismo além da dieta: ativismo vegano em São Paulo. 2010. Dissertação (Mestrado Programa de Pós-graduação em Ciências Sociais da Pontifícia) Universidade Católica de São Paulo, São Paulo, 2010.

OLIVEIRA, S. O Nascimento de uma nova versão de líderes. São Paulo: Integrare, 2010.

PESQUISA de opinião pública sobre vegetarianismo. 2018. Ibope Inteligencia. Disponível em: <https://www.svb.org.br/images/Documentos/JOB_0416_VEGETARIANISMO.pdf >. Acesso em: 13 abr. 2020.

PICCIARELLI, Ronaldo. Global Views on Food. Publicado em: 05/02/2019. Disponível em: <https://www.ipsos.com/pt-br/global-views-food>. Acesso em: 21 abr. 2020.

PRADO, Ana Laura. Negócios faturam com onda de produtos para veganos. Publicado em 30/08/2016. Disponível em: <https://exame.abril.com.br/pme/negocios-faturam-com-onda-deprodutos-para-veganos/>. Acesso em: 21 abr. 2020. 
QUEIROZ, Carolina Andrade; SOLIGUETTI, Debora Fernanda Gonsalves; MORETTI, Sérgio Luiz do Amaral. As principais dificuldades para vegetarianos se tornarem veganos: um estudo com o consumidor brasileiro. Demetra: Alimentação, Nutrição e Saúde, v. 13, n. 3, p. 535-554, 2018.

RADNITZ, C.; BEEZHOLD, B.; DIMATTEO, J. Investigation of lifestyle choices of individuals following a vegan diet for health and ethical reasons. Appetite, v. 90, p. 31 -36, 2015.

SAMPIERI, R. H.; COLLADO, C. F.; LUCIO, P. B. Metodología de la investigación. 4.ed. México: McGraw-Hill, 2006.

SARAIVA, Rutiele Pereira da Silva. Por uma ética antiespecista: o lugar dos animais não humanos na filosofia moral de Tom Regan. 2014. 125f. Dissertação (Mestrado) - Universidade Federal do Ceará, Instituto de cultura e Arte, Programa de PósGraduação em Filosofia, Fortaleza, 2014.

SCHINAIDER, Anelise D. Consumo vegano: o estado da arte e o comportamento do consumidor baseado na teoria do comportamento planejado (TCP). 2018. Dissertação (Mestrado em Agronegócios) - UFRGS, Porto Alegre, 2018.

SILVA, Cecília Onohara da. Juízo moral e pressupostos informacionais: a questão do consumo de carne. 2019. Tese (Doutorado). - Universidade de São Paulo. Instituto de Psicologia, 2019.

SIQUEIRA, Antonio Carlos B. Marketing empresarial, industrial e de Serviços. São Paulo: Saraiva, 2005.

SOBRE a Mr Veggy. Mr. Veggy. 2020. Disponível em: <https://mrveggy.com/sobre/>. Acesso em: 21 abr. 2020.

SOCIEDADE VEGETARIANA BRASILEIRA - SVB. Mercado vegetariano. 2020. Disponível em: 〈https://www.svb.org.br/vegetarianismo1/mercado-vegetariano>. Acesso em: 13 abr. 2020.

SOLOMON, M. R. O comportamento do consumidor: comprando, possuindo e sendo. Porto Alegre: Bookman, 2016.

STEFAN, Amanda Cristina et al. Em defesa dos animais não-humanos: uma análise crítica da teoria utilitarista de Peter Singer. 2018. Dissertação (Mestrado) - Faculdade de Ciências Aplicadas - Universidade Estadual de Campinas, Limeira, 2018.

SUDDATH, Claire. A Brief History of Veganism. Out. 2008. Disponível em:

<https://time.com/3958070/history-of-veganism/>. Acesso 16 abr. 2020.

UNIÃO VEGETARIANA INTERNACIONAL - UVI. Sobre a UVI. 2017. Disponível em:

<https://ivu.org/portuguese/about.html>. Acesso em 06 de nov de 2019.

VEGAN SOCIETY. Definition of veganism. 2020. Disponível em:

<https://www.vegansociety.com/go-vegan/definition-veganism>. Acesso em: 15 de mar de 2020.

VEGAN SOCIETY._. The vegan society 70 anniversary: ripened by human determination.

2014. Disponível em:

<https://www.vegansociety.com/sites/default/files/uploads/Ripened\%20by\%20human\%20determi nation.pdf $>$. Acesso em: 16 abr. 2020. 